\title{
Considerable variation in the concentration of osteopontin in human milk, bovine milk, and infant formulas ${ }^{1}$
}

\author{
L. Schack, ${ }^{*} \dagger$ A. Lange,‡ J. Kelsen,§ J. Agnholt,§ B. Christensen, ${ }^{*}$ T. E. Petersen, ${ }^{*}$ and E. S. Sørensen ${ }^{*} \dagger^{2}$ \\ ${ }^{*}$ Protein Chemistry Laboratory, Department of Molecular Biology, and \\ †Interdisciplinary Nanoscience Center (iNANO), Aarhus University, Aarhus, Denmark \\ ‡Department of Pediatrics, and \\ §Gastro-Immuno Research Laboratory, Department of Medicine V, Aarhus University Hospital, Aarhus, Denmark
}

\begin{abstract}
Osteopontin (OPN) is a multifunctional bioactive protein that is implicated in numerous biological processes such as bone remodeling, inhibition of ectopic calcification, and cellular adhesion and migration, as well as several immune functions. Osteopontin has cytokine-like properties and is a key factor in the initiation of $\mathrm{T}$ helper 1 immune responses. Osteopontin is present in most tissues and body fluids, with the highest concentrations being found in milk. In the present study, ELISA for human and bovine milk OPN were developed and OPN concentration in human breast milk, bovine milk, and infant formulas was measured and compared. The OPN concentration in human milk was measured to approximately $138 \mathrm{mg} / \mathrm{L}$, which corresponds to $2.1 \%$ (wt/wt) of the total protein in human breast milk. This is considerably higher than the corresponding OPN concentrations in bovine milk $(\sim 18 \mathrm{mg} / \mathrm{L})$ and infant formulas $(\sim 9 \mathrm{mg} / \mathrm{L})$. Moreover, bovine milk OPN is shown to induce the expression of the $\mathrm{T}$ helper 1 cytokine IL-12 in cultured human lamina propria mononuclear cells isolated from intestinal biopsies. Finally, the OPN concentration in plasma samples from umbilical cords, 3-mo-old infants, and pregnant and nonpregnant adults was measured. The OPN level in plasma from 3-mo-old infants and umbilical cords was found to be 7 to 10 times higher than in adults. Thus, the high levels of OPN in milk and infant plasma suggest that OPN is important to infants and that ingested milk OPN is likely to induce cytokine production in neonate intestinal immune cells.
\end{abstract}

Key words: osteopontin, human milk, bovine milk, infant formula

Received May 7, 2009.

Accepted July 29, 2009.

${ }^{1}$ Mention of trade names or commercial products in this article is solely for the purpose of providing specific information and does not imply recommendation or endorsement by the authors.

${ }^{2}$ Corresponding author: ess@mb.au.dk

\section{INTRODUCTION}

Milk is an excellent source of nutrition, vitamins, minerals, and energy and it contains several bioactive proteins that play important roles in infant immunity. During the first phase of life, when infants are immunologically immature, breast-feeding provides an effective protection against infections (Lawrence and Pane, 2007); breast-fed infants have a reduced frequency of infectious episodes compared with formula-fed infants (Huffman and Combest, 1990; Cunningham et al., 1991; Dewey et al., 1995). This protective effect of human milk is likely achieved through the numerous bioactive components contained in the milk, which include proteins and peptides with antimicrobial and immune-stimulating properties such as lactoferrin, lactoperoxidase, lysozyme, and IgA (Hanson et al., 2003; Field, 2005). However, a significant protein compositional dissimilarity exists between human milk and that of bovine milk and infant formulas (Hambreus et al., 1977). Human breast milk is evolutionarily optimized to fulfill the needs of the developing infant; hence, efforts have been made to improve the composition of infant formulas to mimic that of breast milk. This is achieved by purifying milk fractions and individual milk proteins and supplementing these to infant formula as is done, for instance, with lactoferrin (Tomita et al., 2002). A less well-characterized bioactive protein that could potentially play a role in neonate and infant immunity and development is the cytokine osteopontin (OPN).

Osteopontin is a multifunctional protein that is implicated in a wide number of biological processes including cell survival, bone remodeling, inhibition of ectopic calcification, and immune modulatory functions (Sodek et al., 2000). The protein is expressed in most tissues and body fluids including blood, urine, bile, and milk (Sodek et al., 2000). Osteopontin is a highly acidic phosphorylated glycoprotein containing an integrinbinding Arg-Gly-Asp (RGD) sequence. Bovine milk OPN contains 27 phosphoseryl residues and 1 phosphothreonine (Sørensen et al., 1995); in human milk, up to 34 phosphoserines and 2 phosphothreonines have been 
identified (Christensen et al., 2005). The phosphorylations are arranged in clusters of 3 to 5 phosphoresidues and are located in the target sequence of the mammary gland casein kinase or casein kinase II (Sørensen et al., 1995; Christensen et al., 2005). This arrangement of phosphorylations is identical to the distribution of phosphate groups on the major milk proteins, the caseins, (Mercier, 1981) as well as component PP3 (Sørensen and Petersen, 1993a). Furthermore, bovine and human milk OPN contain 3 and 5 O-glycosylated threonines, respectively. In milk, OPN is present as an intact protein or in several proteolytically generated N- and Cterminal fragments (Senger et al., 1989; Sørensen and Petersen, 1993b; Sørensen et al., 2003). An N-terminal fragment, which can be generated by proteolytic cleavage close to the RGD sequence (Senger et al., 1989), has been shown to increase its cell binding properties both through the RGD sequence and through exposure of a cryptic integrin binding site (Sodek et al., 2000).

The biological role of OPN in milk is not clear; however, several functions could be hypothesized. Osteopontin has been reported to be involved in mammary gland development and differentiation (Nemir et al., 2000), and high levels of OPN expression have been observed in the mammary gland in early lactation (Rittling and Novick, 1997). Osteopontin has also been reported to interact with the milk proteins lactoferrin, lactoperoxidase, and IgM through electrostatic and affinity interactions (Azuma et al., 2006). This prompted the hypothesis that OPN could potentially act as a transporter of these immunomodulating and antibacterial proteins to their site of action. Furthermore, the highly anionic nature of the protein could enable OPN to form soluble complexes with calcium ions and thereby inhibit unintentional calcium crystallization and precipitation in milk (Gericke et al., 2005). Supporting an inhibitory function of OPN in ectopic calcification, an in vivo model using OPN-deficient mice showed diminished calcification upon exogenous addition of the protein (Ohri et al., 2005). In addition, OPN is involved in the urinary tract's defense against the formation of renal stones because OPN can inhibit growth and aggregation of calcium oxalate monohydrate crystals (Asplin et al., 1998).

Osteopontin has been shown to play a pivotal role in the development and maintenance of immune responses because it influences the function of immune cells such as macrophages, dendritic cells, and T cells (Wang and Denhardt, 2008). The T cells are known to differentiate into 2 major subpopulations, T helper 1 (Th1) and T helper 2 (Th2) cells, differing in the type of cytokines secreted upon antigen stimulation. The most important inducers of the Th1 response are IL-12, IFN- $\gamma$, and type 1 interferon, whereas IL-4 and IL-10 are important inducers of the Th2 response (Santana and Rosenstein, 2003). The generation of a Th1 response is essential for the clearance of intracellular pathogens such as viruses and certain bacteria, but it is also linked to autoimmune diseases when response is excessive. Osteopontin has been shown to be an important early regulator of Th1-mediated immunity by inducing secretion of the Th1 cytokine IL-12 and inhibiting the production of the Th2 cytokine IL-10 (Ashkar et al., 2000). Moreover, several studies have indicated that OPN enhances host resistance to infections (Patarca et al., 1989; Nau et al., 1999; Rollo et al., 2005) and recently we have shown that OPN acts as an opsonin that enhances bacterial phagocytosis (Schack et al., 2009).

Measurements of early and mature human milk showed OPN concentrations of approximately 1,500 and $900 \mathrm{mg} / \mathrm{L}$, respectively (Nagatomo et al., 2004). These values correspond to up to $10 \%$ of the total protein amount in human breast milk, which seems surprisingly high. In the present study, a human OPN ELISA developed in-house and 2 commercial ELISA were used to measure the OPN concentration in human breast milk samples. It was shown that the commercial ELISA, which was used in the aforementioned study (Nagatomo et al., 2004), significantly overestimated the OPN concentration. An ELISA for bovine milk OPN was also developed and used to measure the OPN content in bovine milk and select infant formulas. We demonstrated that the OPN concentration in human milk is considerably higher than in bovine milk and infant formulas and that OPN levels in infant plasma were 10-fold higher than in adults. Finally, we showed that milk OPN was able to induce IL-12 secretion from human lamina propria mononuclear cells (LPMNC) isolated from gut biopsies. Together, these data could suggest that OPN is involved in the infant immune response.

\section{MATERIALS AND METHODS}

\section{Purification of Human and Bovine Milk OPN}

Osteopontin was purified from human milk essentially as described (Senger et al., 1989). However, instead of the final reversed-phase HPLC step, the supernatant resulting from the barium chloride and sodium citrate precipitation was dialyzed against $0.1 \%$ formic acid overnight at $4^{\circ} \mathrm{C}$, centrifuged $(31,000 \times g, 25 \mathrm{~min})$, and the resulting supernatant was lyophilized. To separate full-length OPN ( $\sim 90 \%)$ from the N-terminal fragment $(\sim 10 \%)$, OPN was dissolved in $0.1 M$ ammonium bicarbonate and subjected to gel-filtration chromatography on a Superdex 200 HR10/30 (GE Healthcare, Uppsala, Sweden). The peak corresponding to full-length OPN 
was collected and lyophilized. The purity of the OPN $(+98 \%)$ was verified by SDS-PAGE, reversed phasechromatography, and N-terminal sequencing.

Bovine OPN was purified from fresh pooled bovine milk as described previously (Sørensen and Petersen, 1993b). To increase purity, OPN was further purified by reversed-phase HPLC on a Vydac $\mathrm{C}_{4}$ column (The Separations Group, Hesperia, CA). The purity and concentration of human and bovine OPN were determined by SDS-PAGE, Edman sequence, and AA analyses.

\section{Polyclonal Antibodies}

Immunizations and collection of antiserum were performed at Dako A/S (Glostrup, Denmark) and MedProbe (Oslo, Norway) for bovine and human OPN, respectively. The IgG fraction of the antiserum was purified on a Protein A Sepharose CL-4B column (Uppsala, Sweden). The specificities of the antibodies were checked and verified by Western blotting analyses of milk samples and purified OPN. No cross-reactivity with other milk proteins was observed.

For biotinylation, antibodies were dialyzed 3 times against $500 \mathrm{~mL}$ of $0.1 \mathrm{M}$ sodium borate buffer $(\mathrm{pH} 8.8)$ overnight at $4^{\circ} \mathrm{C}$. One-sixth (vol/vol) of $10 \mathrm{mg} / \mathrm{mL}$ of N-hydroxysuccinimide (BHNS) biotin in dimethylsulfoxide (DMSO) was added to the antibodies. After 4 $\mathrm{h}$ of incubation at room temperature, $20 \mu \mathrm{L}$ of $1 M$ of ammonium bicarbonate per $250 \mu \mathrm{g}$ of BHNS was added to the mixture and further incubated for $10 \mathrm{~min}$ at room temperature. Finally, the biotinylated antibodies were dialyzed twice against $500 \mathrm{~mL}$ of PBS overnight at $4^{\circ} \mathrm{C}$ and the antibody concentration was calculated by measuring the absorbance at $280 \mathrm{~nm}$.

\section{Milk and Plasma Samples}

Milk from 29 mothers aged 22 to $37 \mathrm{yr}$ (mean $=29.6$ yr) was sampled 6 to $58 \mathrm{~d}$ postpartum (mean $=20.4 \mathrm{~d}$ postpartum) at the maternity ward at the University Hospital of Aarhus (Denmark). The milk was obtained by breast pumping and $2 \mathrm{~mL}$ from each milking was sampled and pooled to obtain whole-day milk. The cream was extracted by centrifugation $(3,000 \times g, 5$ min) and the skimmed milk collected, aliquoted, and stored at $-20^{\circ} \mathrm{C}$ until analyses.

Pooled unpasteurized bovine milk samples were obtained at a local dairy over a period of $4 \mathrm{mo}$, pooled, and processed as described for human milk. Five commercially available infant formulas [XO1 and Premium XO (Nam Yang Dairy Products Co. Ltd., Seoul, South Korea), Nan 1 and Nidina (Nestlé, Copenhagen, Denmark), and Allomin 2 (Beauvais, Taastrup, Denmark)] were prepared according to the manufacturers' instructions.

Blood samples were collected from umbilical cords (10 samples), from 3-mo-old infants (10 samples), from nonpregnant adults (10 samples), and from pregnant or postpregnant adults (7 samples) at Aarhus University Hospital, Skejby Sygehus (Denmark). The samples from the pregnant or postpregnant group were collected during the third trimester, at delivery, or 5 to $10 \mathrm{~d}$ after birth. The plasma was prepared immediately after blood collection and was stored at $-80^{\circ} \mathrm{C}$ until analyses.

\section{ELISA Procedures}

For our in-house human OPN ELISA, MaxiSorp immunoassay plates (Thermo Fisher Scientific, Roskilde, Denmark) were incubated with antibodies $(1 \mu \mathrm{g} / \mathrm{mL}$ in $0.1 \mathrm{M}$ of sodium carbonate, $\mathrm{pH} 9.8$ ) overnight at $4^{\circ} \mathrm{C}$ and were subsequently washed extensively with PBS buffer and blocked with 3\% BSA. Milk samples were diluted 10,000 to 30,000-fold in Tris-Tween buffer $(0.1 \%$ Tween 20, $10 \mathrm{~m} M$ of Tris- $\mathrm{HCl}, 1 \mathrm{M}$ of $\mathrm{NaCl}, 30 \mathrm{mM}$ of $\mathrm{CaCl}_{2}, 2 \% \mathrm{BSA}, \mathrm{pH} 7.4$ ), applied to the assay plate, and incubated for $1 \mathrm{~h}$ at room temperature, followed by extensive washing. Captured OPN was detected by incubation with $0.5 \mu \mathrm{g}$ of biotinylated polyclonal antibody per well followed by incubation with 100 $\mu \mathrm{L}$ of horseradish peroxidase-conjugated streptavidin (diluted 1:8,000) for $1 \mathrm{~h}$ at room temperature. Color development was obtained using 1,2-phenylendiaminedihydrochloride (OPD) tablets (Dako) and the reaction was stopped by addition of $1 M$ of $\mathrm{H}_{2} \mathrm{SO}_{4}$. Color intensity was measured at $490 \mathrm{~nm}$ using an ELISA reader (Bio-tek Instruments Inc., Winooski, VT). Full-length OPN purified from human milk was quantified by AA analysis and used as the standard. All analyses were performed in triplicate. Two commercial human OPN ELISA were purchased from R \& D Systems (Abingdon, UK) and IBL (Immuno-Biological Laboratories; Gunma, Japan), respectively, and were used according to the manufacturers' descriptions. The OPN concentration in human milk was measured using the in-house human OPN ELISA as well as the ELISA from R \& D Systems and IBL. The ELISA from R \& D Systems was also used to measure the OPN concentration in plasma samples from umbilical cords, 3-mo-old infants, and pregnant and nonpregnant adults.

A bovine milk OPN ELISA was developed as described for the human milk OPN ELISA using antibodies raised against bovine milk OPN (Dako) and purified full-length bovine milk OPN as standard. The in-house bovine OPN ELISA was used to measure OPN concentration in bovine milk and in infant formulas. The 
analyses of the infant formulas were based on $125 \mathrm{~g} / \mathrm{L}$ of formula solutions and the result was calculated as milligrams of OPN per liter of ready-to-feed formula.

The protein concentration in the milk samples was measured by Bradford analyses with BSA as the standard using a Bio-Rad protein assay kit (Richmond, CA).

\section{IL-12 Expression in Human LPMNC}

Mucosal biopsies from colons of healthy adults were taken during colonoscopy. The biopsies were cultured in the presence of IL-2 and IL- 4 as described (Agnholt and Kaltoft, 2001). This culture system promoted the growth of mucosal T cells, which showed preserved cellular features and phenotype of $\mathrm{CD} 4^{+} \mathrm{T}$ cells (Kelsen et al., 2005). High purity of $\mathrm{CD} 4^{+} \mathrm{T}$ cells was reached after 3 to 4 wk of culture; however, trace amounts of other cell types including monocytes were occasionally found. Culture plates were coated overnight at $4^{\circ} \mathrm{C}$ by incubation with $1 \mathrm{~mL}$ of PBS in the presence or absence of bovine milk OPN $(1 \mathrm{mg} / \mathrm{mL})$. The LPMNC were cultured $\left(10^{6}\right.$ cells $\left./ \mathrm{mL}\right)$ for $24 \mathrm{~h}$ and, subsequently, aliquots of supernatants were sampled for analyses. Cytokine-matched antibody pairs were obtained from R \& D Systems for determination of IL-12. The detecting antibodies were all biotinylated. A time-resolved fluorometric assay applying Europium $\left(\mathrm{Eu}^{3+}\right)$-labeled streptavidin and a Delphia 1234 fluorometer (Wallac, Turku, Finland) were used to determine the levels of IL-12. Obtained values were averages of 3 ELISA readings in triplicate experiments and were representative of 3 healthy persons.

\section{Statistical Analysis}

Statistical analysis of data was done by Student's $t$-test. Difference was considered to be statistically significant at $P<0.05$.

\section{Ethical Considerations}

The study of human samples was approved by the local ethics committee of the County of Aarhus, Denmark. Blood samples were taken anonymously from a scientific blood bank containing blood from infants and umbilical cords.

\section{RESULTS}

\section{OPN in Human Milk}

The OPN concentration in 29 breast milk samples obtained 6 to $58 \mathrm{~d}$ postpartum was measured by a newly developed in-house ELISA. Concurrently, the protein concentration in the samples was measured by Bradford analysis. The combined results are shown in Table 1. The OPN concentration in human milk ranged from 18 to $322 \mathrm{mg} / \mathrm{L}$ with an average value of $138 \mathrm{mg} / \mathrm{L}$ (SD $=79$ ). The protein content of the milk samples varied from 1,834 to $15,430 \mathrm{mg} / \mathrm{L}$, with an average value of $8,062 \mathrm{mg} / \mathrm{L}(\mathrm{SD}=3,680)$. Thus, according to these analyses, OPN constitutes an average of $2.1 \%$ (wt/wt; $\mathrm{SD}=1.4$ ) of the total protein in human milk. The OPN content in 14 of the milk samples was also measured with ELISA kits from R \& D Systems and IBL (Table 2). The average OPN content for the ELISA from R \& D Systems was $144 \mathrm{mg} / \mathrm{L}$ (SD 83), which is not significantly different $(P=0.45)$ from the value of $122 \mathrm{mg} / \mathrm{mL}(\mathrm{SD}=70)$ obtained with our in-house ELISA. In contrast, the OPN concentration measured with the ELISA from IBL was $1,175 \mathrm{mg} / \mathrm{mL}$ (SD = $1,137)$, which is significantly higher $(P<0.01)$ than the values obtained with the in-house ELISA. The results obtained with the 3 tests were well-correlated, with correlation coefficients squared in excess of 0.8 (Table 1). In conclusion, the OPN concentrations measured by the newly designed in-house ELISA were in close agreement with the data obtained with the ELISA kit from R \& D Systems, whereas values measured with the IBL kit were approximately an order of magnitude higher.

To confirm the finding of an OPN concentration of $138 \mathrm{mg} / \mathrm{L}$ in human breast milk, purified full-length human milk OPN was quantified by AA analysis and a sample containing $10 \mathrm{ng}$ of OPN was measured by the in-house ELISA and the 2 commercial ELISA. Contents of $10 \mathrm{ng}$ and $13 \mathrm{ng}$ were measured with the in-house ELISA and the R \& D ELISA, respectively, whereas the IBL ELISA showed a content of 114 ng. This confirms our findings and emphasizes that the ELISA from IBL considerably overestimated the content of OPN in milk.

\section{OPN in Bovine Milk and Infant Formulas}

The level of OPN in bovine milk was measured by use of the in-house bovine OPN ELISA. The OPN concentration in bovine milk was measured as $18 \mathrm{mg} / \mathrm{L}$ and the total protein content was $35 \mathrm{~g} / \mathrm{L}$ according to the literature. Consequently, the OPN content in bovine milk is $0.05 \%$ (wt/wt) of the total protein. Hence, the average OPN concentration related to total protein is significantly higher in human breast milk than in bovine milk (2.1 vs. $0.05 \%)$. This suggests that the OPN content in infant formulas, based on bovine milk, may also be considerably lower than the concentration found in human milk. Consequently, we measured the concentration of OPN in 5 commercially available in- 
Table 1. Osteopontin (OPN) concentration in human breast milk from 29 women

\begin{tabular}{|c|c|c|c|c|c|}
\hline Sample & $\begin{array}{c}\text { Age of } \\
\text { mother (yr) }\end{array}$ & $\begin{array}{c}\text { Time } \\
\text { postpartum (d) }\end{array}$ & $\begin{array}{c}\text { OPN }_{\text {concentration }^{1}}(\mathrm{mg} / \mathrm{L})\end{array}$ & $\begin{array}{c}\text { Total protein } \\
\text { concentration }^{2}(\mathrm{mg} / \mathrm{L})\end{array}$ & $\begin{array}{l}\text { OPN/total protein } \\
\text { (wt/wt, \%) }\end{array}$ \\
\hline 1 & 28 & 58 & 66 & 8,550 & 0.77 \\
\hline 2 & 35 & 13 & 257 & 8,327 & 3.09 \\
\hline 4 & 25 & 6 & 65 & 11,868 & 0.55 \\
\hline 5 & 31 & 9 & 46 & 15,430 & 0.30 \\
\hline 6 & 25 & 12 & 22 & 11,442 & 0.19 \\
\hline 10 & 23 & 12 & 212 & 10,936 & 1.94 \\
\hline 11 & 30 & 10 & 105 & 12,576 & 0.83 \\
\hline 12 & 31 & 27 & 157 & 5,376 & 2.92 \\
\hline 13 & 30 & 17 & 185 & 4,459 & 4.15 \\
\hline 14 & 31 & 37 & 103 & 5,568 & 1.85 \\
\hline 15 & 30 & 10 & 239 & 12,628 & 1.89 \\
\hline 21 & 32 & 22 & 47 & 1,834 & 2.56 \\
\hline 22 & 35 & 28 & 171 & 5,219 & 3.28 \\
\hline 23 & 28 & 28 & 192 & 4,602 & 4.17 \\
\hline 24 & 30 & 17 & 245 & 8,832 & 2.77 \\
\hline 25 & 27 & 22 & 154 & 3,426 & 4.50 \\
\hline 26 & 30 & 11 & 206 & 4,069 & 5.06 \\
\hline 27 & 29 & 15 & 175 & 4,738 & 3.69 \\
\hline 28 & 37 & 15 & 40 & 6,520 & 0.61 \\
\hline 29 & 27 & 28 & 203 & 11,562 & 1.76 \\
\hline Mean & 29.6 & 20.4 & 138 & 8,062 & 2.1 \\
\hline SD & 3.5 & 11.3 & 79 & 3,680 & 1.4 \\
\hline
\end{tabular}

${ }^{1}$ OPN concentration measured with an in-house-developed ELISA.

${ }^{2}$ Protein concentration determined by Bradford analysis.

fant formulas (Table 3) and found values in the range of 5.3 to $13.0 \mathrm{mg} / \mathrm{mL}$ in ready-to-use formulas.

\section{OPN-Induced IL-12 Expression in Human LPMNC}

Previous studies from our laboratory have shown that OPN is partly resistant to digestion by human neonatal gastric juice (Chatterton et al., 2004) and that a fraction of the ingested OPN is therefore expected to reach the intestine in intact form. To evaluate the potential immune modulatory effect of orally ingested OPN, LPMNC (which represent the first line of the immune system at the gut mucosal surface) were stimulated with OPN and the IL-12 secretion was measured. Upon stimulation of LPMNC with OPN, an IL-12 production of $16.6 \mathrm{pg} / \mathrm{mL}$ (SD 2.1) was observed, which is a significant increase $(P<0.01)$ compared with 3.3 $\mathrm{pg} / \mathrm{mL}$ (SD 3.2) produced by the control cells (data not shown). We cannot define the exact cellular origin of the secreted IL-12. In the present culture system we obtained a purity of $\mathrm{T}$ cells of approximately $95 \%$, but remaining monocytes may also contribute to the IL-12 production (Sato et al., 2005). In conclusion, we showed that bovine milk OPN is able to induce expression of the potent Th1 cytokine IL-12 in human intestinal immune cells, indicating a role in the modulation of intestinal immunity.

\section{OPN in Plasma}

The high concentration of OPN in human milk suggests that it could play a role in the development of the infant. To examine potential differences in OPN content in blood from adults and infants, plasma samples from umbilical cords, 3-mo-old infants, nonpregnant adults, and pregnant or postpregnant adults were analyzed. The OPN concentration in plasma from adults was measured to be $35 \mathrm{ng} / \mathrm{mL}$ (Figure 1), which is in agreement with previously reported blood values ( $\mathrm{Ag}$ nholt et al., 2007; Sennels et al., 2007). No difference was observed between the adult nonpregnant and the pregnant or postpregnant groups. In comparison, the OPN concentrations in plasma from 3-mo-old infants and from umbilical cords were $342 \mathrm{ng} / \mathrm{mL}$ and 263 $\mathrm{ng} / \mathrm{mL}$, respectively (Figure 1), which is significantly higher than the levels in adults $(P<0.01)$. 


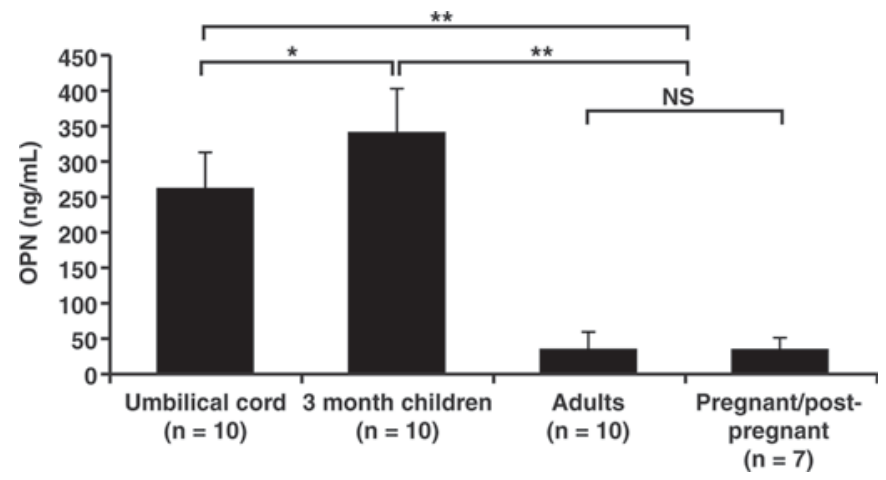

Figure 1. Osteopontin (OPN) concentrations in plasma from umbilical cords, 3-mo-old infants, adults, and pregnant or postpregnant women, measured by ELISA. The number of samples analyzed for each group is indicated and standard errors are represented with vertical bars. *The OPN content in plasma from 3-mo-old infants was significantly higher than that from umbilical cords $(P<0.05)$. ${ }^{*}$ The OPN content in plasma from umbilical cords and from 3-mo-old infants were both significantly higher than that from adults and pregnant or postpregnant women $(P<0.01)$.

\section{DISCUSSION}

Osteopontin is a multifunctional protein that is implicated in numerous cellular and physiological processes (Sodek et al., 2000). It is present in high concentrations in milk, where it can be hypothesized to be involved in the development and maturation of the infant immune system. Surprisingly high concentrations of OPN were found in human breast milk by use of an OPN ELISA from IBL. Osteopontin concentrations in early milk (3-7 d) and in mature milk (1 mo postpartum) were reported at $1,493.4 \mathrm{mg} / \mathrm{L}$ and $896.3 \mathrm{mg} / \mathrm{L}$, respectively (Nagatomo et al., 2004). Though it has previously been reported that the OPN concentration in milk is quite high (Senger et al., 1989; Sørensen et al., 2003), these values, which suggest that OPN should constitute more than $10 \%$ of the total protein in breast milk, seemed to be overestimated.

To estimate the concentration of OPN more precisely, we designed an in-house OPN ELISA based on antibodies raised against highly purified full-length milk OPN. Subsequently, we analyzed milk samples from 29 women and found an average OPN concentration of $138 \mathrm{mg} / \mathrm{mL}$ (SD 79; Table 1). The values measured in this study comprise the natural mixture of full-length $(>80 \%)$ and cleaved OPN that is present in milk. Depending on the degree of proteolysis taking place in the milk, OPN concentration may deviate slightly from the reported values. For example, the value will be slightly higher if a smaller OPN fragment is present in milk and not recognized by the antibodies used in this ELISA. Conversely, the concentration might be slightly lower if smaller fragments or peptides are recognized and converted to the mass of the full-length protein
Table 2. Osteopontin (OPN) concentrations in milk samples analyzed with an in-house-developed ELISA and ELISA from R \& D Systems and $\mathrm{IBL}^{1}$

\begin{tabular}{lccc}
\hline & \multicolumn{3}{c}{ OPN concentration $(\mathrm{mg} / \mathrm{L})$} \\
\cline { 2 - 4 } Sample & In-house & R \& D & IBL $^{3}$ \\
\hline 1 & 66 & 86 & 582 \\
2 & 257 & 309 & 4,075 \\
3 & 201 & 182 & 1,962 \\
4 & 65 & 71 & 394 \\
5 & 46 & 66 & 250 \\
6 & 22 & 25 & 172 \\
7 & 102 & 152 & 601 \\
8 & 114 & 227 & 1,342 \\
9 & 67 & 63 & 203 \\
10 & 212 & 267 & 2,810 \\
11 & 105 & 98 & 255 \\
12 & 157 & 144 & 1,356 \\
13 & 185 & 182 & 1,447 \\
14 & 103 & 141 & 996 \\
Mean & $122^{\mathrm{a}}$ & $144^{\mathrm{a}}$ & $1,175^{\mathrm{b}}$ \\
SD & 70 & 83 & 1,137 \\
\hline
\end{tabular}

a-b Mean values within a row with unlike superscript letters are significantly different $(P<0.01)$.

${ }^{1}$ Regression equations: In-house versus $\mathrm{R} \& \mathrm{D}: 1.07 \mathrm{x}+13.88\left(\mathrm{r}^{2}=\right.$ $0.81)$; in-house versus IBL: $14.9 \mathrm{x}-638.30\left(\mathrm{r}^{2}=0.85\right)$; $\mathrm{R} \& \mathrm{D}$ versus IBL: $12.65 \mathrm{x}-640.11\left(\mathrm{r}^{2}=0.85\right)$.

${ }^{2} \mathrm{R} \&$ D Systems, Abingdon, UK.

${ }^{3}$ IBL (Immuno-Biological Laboratories), Gunma, Japan.

using the standard curve. The results obtained with our in-house ELISA corresponded well with those obtained with the ELISA from R \& D Systems, whereas values approximately 10 times higher were measured with the ELISA from IBL (Table 2). This is in line with the results of recent comparisons of commercial OPN ELISA, which also showed substantial variation in the OPN concentration in plasma depending on the type of ELISA used (Vordermark et al., 2006; Plumer et al., 2008). For example, an approximately 10-fold higher

Table 3. Osteopontin (OPN) concentrations in selected infant formulas compared with bovine and human milk

\begin{tabular}{lc}
\hline Item & OPN concentration $^{1}(\mathrm{mg} / \mathrm{L})$ \\
\hline Infant formula $^{2}$ & \\
XO1 & 7.9 \\
Premium XO & 13.0 \\
Nan 1 & 10.3 \\
Nidina 1 & 5.3 \\
Allomin 2 & 6.4 \\
Milk & 18 \\
Bovine milk & 138 \\
Human milk & \\
\hline
\end{tabular}

${ }^{1}$ The OPN concentration was measured in ready-to-feed formulas based on $125 \mathrm{~g} / \mathrm{L}$ of powder.

${ }^{2}$ XO1 and Premium XO manufactured by Nam Yang Dairy Products Co. Ltd. (Seoul, South Korea); Nan 1 and Nidina 1 manufactured by Nestlé (Copenhagen, Denmark); Allomin 2 manufactured by Beauvais (Taastrup, Denmark). 
concentration of human full-length OPN was measured with the IBL ELISA compared with 3 other ELISA (Plumer et al., 2008).

The high OPN values measured with the IBL ELISA may be explained by the fact that this ELISA had not been validated for measurements in milk. In contrast, our in-house ELISA was based on polyclonal antibodies raised against the human milk protein and utilized purified human milk OPN as the standard. Neither the epitopes recognized by the antibodies used in the $\mathrm{R}$ \& D ELISA nor the nature of the OPN used for the immunizations were disclosed. However, the assay has, among others, been validated for quantitative determination of OPN in human milk, according to the manufacturer's instructions. Based on the highly consistent values obtained with our in-house ELISA and the $\mathrm{R} \&$ D ELISA, we concluded that the concentration of OPN in human breast milk was approximately $138 \mathrm{mg} / \mathrm{L}$, with considerable individual variation. Likewise, we determined the OPN concentration in bovine milk and 5 selected infant formulas to be $18 \mathrm{mg} / \mathrm{L}$ and an average of $8.6 \mathrm{mg} / \mathrm{L}$, respectively (Table 3). Thus, the concentration of OPN in bovine milk and infant formula was considerably lower than that in human milk.

In this study, we measured the OPN plasma levels in umbilical cords, infants, pregnant adults, and pregnant or postpregnant adults and found a surprisingly high OPN level in the umbilical cord and infant plasma (Figure 1). Thus, the OPN plasma level varies considerably from infancy to adulthood. High plasma OPN levels have been reported in several pathological processes, including Crohn's disease (Sato et al., 2005; Agnholt et al., 2007), multiple sclerosis (Vogt et al., 2003), rheumatoid arthritis (Ohshima et al., 2002), and especially in several types of cancer (Rodrigues et al., 2007), in some of which OPN has also been suggested as a clinical marker of metastatic disease. The high level of OPN in infant plasma suggests that OPN plays a natural role in infant development and that a high plasma concentration of OPN is not linked to pathologic conditions but rather can be a natural part of infant development.

The present data show that infant formulas and bovine milk have a significantly lower content of OPN than human breast milk. This could be important for infant immunity because OPN has been shown to possess a key role in the development of Th1 immunity as well as to enhance host resistance to infections (Nau et al., 1999; Ashkar et al., 2000). We showed that OPN induced the production of the Th1 cytokine IL-12 in cultured LPMNC (which represent the first line of the immune system at the gut mucosal surface). Thus, the intestinal immune system may be modulated by ingested OPN. This is further supported by the observation that milk OPN is partially resistant to proteolysis by neonatal gastric juice (Chatterton et al., 2004). Thus, part of the ingested OPN survives the passage through the infant's stomach and reaches the immune cells present in the intestine. The ingested OPN might further act directly against pathogenic bacteria in the gastrointestinal tract; we have recently shown that OPN is able to opsonize bacteria, which leads to an enhanced phagocytosis (Schack et al., 2009). Supplementation of infant formula with OPN could therefore potentially provide the infant with an important immunological factor.

\section{ACKNOWLEDGMENTS}

We acknowledge Lise Møller Fogh (Aarhus University, Denmark) for excellent technical assistance. The present study was supported by grants from the Danish Dairy Research Foundation (Aarhus, Denmark), Arla Foods amba (Aarhus, Denmark), The Carlsberg Foundation (Copenhagen, Denmark), and the Milk Protein Research Consortium (Aarhus University, Denmark).

\section{REFERENCES}

Agnholt, J., and K. Kaltoft. 2001. In situ activated intestinal T cells expanded in vitro-without addition of antigen-produce IFNgamma and IL-10 and preserve their function during growth. Exp. Clin. Immunogenet. 18:213-225.

Agnholt, J., J. Kelsen, L. Schack, C. L. Hvas, J. F. Dahlerup, and E. S. Sørensen. 2007. Osteopontin, a protein with cytokine-like properties, is associated with inflammation in Crohn's disease. Scand. J. Immunol. 65:453-460.

Ashkar, S., G. F. Weber, V. Panoutsakopoulou, M. E. Sanchirico, M. Jansson, S. Zawaideh, S. R. Rittling, D. T. Denhardt, M. J. Glimcher, and H. Cantor. 2000. Eta-1 (osteopontin): An early component of type-1 (cell-mediated) immunity. Science 287:860864.

Asplin, J. R., D. Arsenault, J. H. Parks, F. L. Coe, and J. R. Hoyer. 1998. Contribution of human uropontin to inhibition of calcium oxalate crystallization. Kidney Int. 53:194-199.

Azuma, N., A. Maeta, K. Fukuchi, and C. Kanno. 2006. A rapid method for purifying osteopontin from bovine milk and interaction between osteopontin and other milk proteins. Int. Dairy J. $16: 370-378$.

Chatterton, D. E. W., J. T. Rasmussen, C. W. Heegaard, E. S. Sørensen, and T. E. Petersen. 2004. In vitro digestion of novel milk protein ingredients for use in infant formulas: Research on biological functions. Trends Food Sci. Technol. 15:373-383.

Christensen, B., M. S. Nielsen, K. F. Haselmann, T. E. Petersen, and E. S. Sørensen. 2005. Posttranslationally modified residues of native human osteopontin are located in clusters. Identification of thirty-six phosphorylation and five O-glycosylation sites and their biological implications. Biochem. J. 390:285-292.

Cunningham, A. S., D. B. Jelliffe, and E. F. Jelliffe. 1991. Breastfeeding and health in the 1980s: A global epidemiologic review. J. Pediatr. 118:659-666.

Dewey, K. G., M. J. Heinig, and L. A. Nommsen-Rivers. 1995. Differences in morbidity between breast-fed and formula-fed infants. J. Pediatr. 126:696-702.

Field, C. J. 2005. The immunological components of human milk and their effect on immune development in infants. J. Nutr. 135:1-4.

Gericke, A., C. Qin, L. Spevak, Y. Fujimoto, W. T. Butler, E. S. Sørensen, and A. L. Boskey. 2005. Importance of phosphorylation for osteopontin regulation of biomineralization. Calcif. Tissue Int. 77:45-54. 
Hambreus, L., E. Forsum, and B. Lönnerdal. 1977. Nutritional aspects of breast milk versus cow's milk formula. Pages 116-124 in Food and Immunology, Symposia of the Swedish Nutrition Foundation. Vol. XIII. L. Hambreus, L.-Å. Hanson, and H. McFarlane, ed. Almqvist and Wiksell, Uppsala, Sweden.

Hanson, L. A., M. Korotkova, and E. Telemo. 2003. Breast-feeding, infant formulas, and the immune system. Ann. Allergy Asthma Immunol. 90:59-63.

Huffman, S. L., and C. Combest. 1990. Role of breast-feeding in the prevention and treatment of diarrhoea. J. Diarrhoeal Dis. Res. $8: 68-81$.

Kelsen, J., J. Agnholt, H. J. Hoffmann, J. L. Romer, C. L. Hvas, and J. F. Dahlerup. 2005. FoxP3 $(+) \mathrm{CD} 4(+) \mathrm{CD} 25(+)$ T cells with regulatory properties can be cultured from colonic mucosa of patients with Crohn's disease. Clin. Exp. Immunol. 141:549557.

Lawrence, R. M., and C. A. Pane. 2007. Human breast milk: Current concepts of immunology and infectious diseases. Curr. Probl. Pediatr. Adolesc. Health Care 37:7-36.

Mercier, J. C. 1981. Phosphorylation of caseins, present evidence for an amino acid triplet code posttranslationally recognized by specific kinases. Biochimie 63:1-17.

Nagatomo, T., S. Ohga, H. Takada, A. Nomura, S. Hikino, M. Imura, K. Ohshima, and T. Hara. 2004. Microarray analysis of human milk cells: Persistent high expression of osteopontin during the lactation period. Clin. Exp. Immunol. 138:47-53.

Nau, G. J., L. Liaw, G. L. Chupp, J. S. Berman, B. L. Hogan, and R. A. Young. 1999. Attenuated host resistance against Mycobacterium bovis BCG infection in mice lacking osteopontin. Infect. Immun. 67:4223-4230.

Nemir, M., D. Bhattacharyya, X. Li, K. Singh, A. B. Mukherjee, and B. B. Mukherjee. 2000. Targeted inhibition of osteopontin expression in the mammary gland causes abnormal morphogenesis and lactation deficiency. J. Biol. Chem. 275:969-976.

Ohri, R., E. Tung, R. Rajachar, and C. M. Giachelli. 2005. Mitigation of ectopic calcification in osteopontin-deficient mice by exogenous osteopontin. Calcif. Tissue Int. 76:307-315.

Ohshima, S., N. Yamaguchi, K. Nishioka, T. Mima, T. Ishii, M. Umeshita-Sasai, H. Kobayashi, M. Shimizu, Y. Katada, S. Wakitani, N. Murata, S. Nomura, H. Matsuno, R. Katayama, S. Kon, M. Inobe, T. Uede, I. Kawase, and Y. Saeki. 2002. Enhanced local production of osteopontin in rheumatoid joints. J. Rheumatol. 29:2061-2067.

Patarca, R., G. J. Freeman, R. P. Singh, F. Y. Wei, T. Durfee, F. Blattner, D. C. Regnier, C. A. Kozak, B. A. Mock, H. C. Morse 3rd, T. R. Jerrells, and H. Cantor. 1989. Structural and functional studies of the early $\mathrm{T}$ lymphocyte activation 1 (Eta-1) gene. Definition of a novel $\mathrm{T}$ cell-dependent response associated with genetic resistance to bacterial infection. J. Exp. Med. 170:145161.

Plumer, A., H. Duan, S. Subramaniam, F. L. Lucas, S. Miesfeldt, A. K. Ng, and L. Liaw. 2008. Development of fragment-specific osteopontin antibodies and ELISA for quantification in human metastatic breast cancer. BMC Cancer 8:38-48.

Rittling, S. R., and K. E. Novick. 1997. Osteopontin expression in mammary gland development and tumorigenesis. Cell Growth Differ. 8:1061-1069.

Rodrigues, L. R., J. A. Teixeira, F. L. Schmitt, M. Paulsson, and H. Lindmark-Mansson. 2007. The role of osteopontin in tumor progression and metastasis in breast cancer. Cancer Epidemiol. Biomarkers Prev. 16:1087-1097.

Rollo, E. E., S. J. Hempson, A. Bansal, E. Tsao, I. Habib, S. R. Rittling, D. T. Denhardt, E. R. Mackow, and R. D. Shaw. 2005. The cytokine osteopontin modulates the severity of rotavirus diarrhea. J. Virol. 79:3509-3516.

Santana, M. A., and Y. Rosenstein. 2003. What it takes to become an effector T cell: The process, the cells involved, and the mechanisms. J. Cell. Physiol. 195:392-401.

Sato, T., T. Nakai, N. Tamura, S. Okamoto, K. Matsuoka, A. Sakuraba, T. Fukushima, T. Uede, and T. Hibi. 2005. Osteopontin/Eta-1 upregulated in Crohn's disease regulates the Th1 immune response. Gut 54:1254-1262.

Schack, L., R. Stapulionis, B. Christensen, E. Kofod-Olsen, U. B. Skov Sørensen, T. Vorup-Jensen, E. S. Sørensen, and P. Höllsberg. 2009. Osteopontin enhances phagocytosis through a novel osteopontin receptor, the alphaXbeta2 integrin. J. Immunol. 182:6943-6950.

Senger, D. R., C. A. Perruzzi, A. Papadopoulos, and D. G. Tenen. 1989. Purification of a human milk protein closely similar to tumorsecreted phosphoproteins and osteopontin. Biochim. Biophys. Acta 996:43-48.

Sennels, H. P., S. Jacobsen, T. Jensen, M. S. Hansen, M. Ostergaard, H. J. Nielsen, and S. Sørensen. 2007. Biological variation and reference intervals for circulating osteopontin, osteoprotegerin, total soluble receptor activator of nuclear factor kappa B ligand and high-sensitivity C-reactive protein. Scand. J. Clin. Lab. Invest. 67:821-835.

Sodek, J., B. Ganss, and M. D. McKee. 2000. Osteopontin. Crit. Rev. Oral Biol. Med. 11:279-303.

Sørensen, E. S., P. Højrup, and T. E. Petersen. 1995. Posttranslational modifications of bovine osteopontin: Identification of twenty-eight phosphorylation and three O-glycosylation sites. Protein Sci. 4:2040-2049.

Sørensen, E. S., and T. E. Petersen. 1993a. Phosphorylation, glycosylation and amino acid sequence of component PP3 from the proteose peptone fraction of bovine milk. J. Dairy Res. 60:535542

Sørensen, E. S., and T. E. Petersen. 1993b. Purification and characterization of three proteins isolated from the proteose peptone fraction of bovine milk. J. Dairy Res. 60:189-197.

Sørensen, S., S. J. Justesen, and A. H. Johnsen. 2003. Purification and characterization of osteopontin from human milk. Protein Expr. Purif. 30:238-245.

Tomita, M., H. Wakabayashi, K. Yamauchi, S. Teraguchi, and H. Hayasawa. 2002. Bovine lactoferrin and lactoferricin derived from milk: Production and applications. Biochem. Cell Biol. 80:109112.

Vogt, M. H., L. Lopatinskaya, M. Smits, C. H. Polman, and L. Nagelkerken. 2003. Elevated osteopontin levels in active relapsingremitting multiple sclerosis. Ann. Neurol. 53:819-822.

Vordermark, D., H. M. Said, A. Katzer, T. Kuhnt, G. Hansgen, J. Dunst, M. Flentje, and M. Bache. 2006. Plasma osteopontin levels in patients with head and neck cancer and cervix cancer are critically dependent on the choice of ELISA system. BMC Cancer 6:207-212.

Wang, K. X., and D. T. Denhardt. 2008. Osteopontin: Role in immune regulation and stress responses. Cytokine Growth Factor Rev. 19:333-345. 